\title{
Short-term use of "ECMELLA" in the context of fulminant eosinophilic myocarditis with cardiogenic shock
}

\author{
Mintje Bohné ${ }^{1}$ Da-Un Chung ${ }^{1}$, Eike Tigges ${ }^{1}$, Hendrick van der Schalk', Daniela Waddell ${ }^{1}$, Niklas Schenker', \\ Stephan Willems ${ }^{1}$, Karin Klingel ${ }^{2}$, Dietmar Kivelitz ${ }^{3}$ and Edda Bahlmann ${ }^{1 *} \mathbb{D}$
}

\begin{abstract}
Background: Eosinophilic myocarditis (EM) is a rare form of myocarditis. Clinical presentation is various, includes cardiogenic shock and can often be fatal. Diagnosis is based on myocardial eosinophilic infiltration in endomyocardial biopsy. Mechanical circulatory support (MCS) is often required in patients suffering from severe cardiogenic shock. Among the available MCS options the "ECMELLA" concept, a combination of left ventricular venting by Impella ${ }^{\circledR}$ device and extracorporeal life support (ECLS) is possibly able to provide the necessary time frame for diagnostics and initiation of anti-inflammatory medication in patients with fulminant myocarditis.
\end{abstract}

Case presentation: We report a case of a 38-year-old woman who was presented to us in severe cardiogenic shock, quickly requiring hemodynamic support by an Impella $C \mathrm{P}^{\circledR}$ device. Further dramatic hemodynamic deterioration accompanied by multi-organ dysfunction required escalation of MCS via ECLS as veno-arterial extracorporeal membrane oxygenation (VA-ECMO). After histopathological diagnosis of EM, our patient was put on immunosuppressive therapy with prednisolone. Recovery of both right and left ventricular function allowed explanation of VA-ECMO on day 4 and further hemodynamic improvement allowed removal of the Impella ${ }^{\circledR}$ device on day 9 . The patient was discharged after 7 weeks with fully restored cardiac function and in a good neurological state.

Conclusions: In severe cardiac shock due to fulminant EM the ECMELLA concept as bridge-to-recovery seems to be a valid option to provide the required time for diagnostics and specific therapy.

Keywords: Eosinophilic myocarditis, Mechanical circulatory support, ECMELLA, Bridge-to-recovery

\section{Background}

Eosinophilic myocarditis (EM) is a rare form of myocarditis that often presents fulminantly with a high mortality-rate during the acute phase [1]. EM is characterized by myocardial inflammation with eosinophilic infiltration and has been reported in association with hypersensitivity reactions [2], immune-mediated disorders such as eosinophilic granulomatosis with polyangiitis [3],

\footnotetext{
*Correspondence: e.bahlmann@asklepios.com

${ }^{1}$ Department of Cardiology, Asklepios Clinic St. Georg, Lohmühlenstraße

5, 20099 Hamburg, Germany

Full list of author information is available at the end of the article
}

parasitic infections [4], cancer [5] and pregnancy [1]. In a large series of 179 published hospitalized cases with histologically proven EM, reported in 2017 by Brambatti et al., 35\% remained with unknown underlying causes, thus classified as idiopathic or undefined [1]. Diagnosis is based on myocardial eosinophilic infiltration in endomyocardial biopsy $[1,6]$ and is often discovered only on postmortem examination [7]. In-hospital mortality due to heart failure is reported in $22.3 \%$, increasing to $36.1 \%$ in hypersensitivity EM, the most frequent condition [1]. Particularly, fulminant EM with concomitant cardiogenic shock is associated with high in-hospital mortality [8] 
and, besides inotropic support, may require mechanical circulatory support (MCS), such as extracorporeal life support (ECLS) as a bridge to myocardial recovery [1, 9-12]. Veno-arterial extracorporeal membrane oxygenation (VA-ECMO) is an established ECLS in severe cardiogenic shock [13-15]. However, increase in systemic afterload and left ventricular (LV) end diastolic pressure are hemodynamic consequences inherent to this type of MCS, potentially impeding myocardial recovery. A combination with antegrade MCS via the antegrade LVto-aorta Impella ${ }^{\circledR}$ microaxial device (Abiomed. Danvers, MA, USA) for LV-unloading has been described as beneficial when compared to VA-ECMO alone [16, 17]. Combining both, Impella ${ }^{\circledR}$ and ECLS is called "ECMELLA" or "ECPELLA" concept [10]. To the best of our knowledge, we present the first case of a fulminate cardiogenic shock due to EM successfully using the "ECMELLA" approach as a bridge to recovery.

\section{Case presentation}

A 38-year-old woman presented to our emergency department with intermitting fever for the past 4 weeks, accompanied by unproductive cough, headache and dizziness, which she self-medicated with acetaminophen and metamizole. On the day of admission, she also reported nausea and abdominal pain. Seven months ago, she had had an uncomplicated delivery of a healthy child, preceded by an uneventful pregnancy. She had a medical history of radiochemotherapy for Hodgkin's disease in 2004 and had been diagnosed with ulcerative colitis in 1998, currently being medicated with mesalazine. A previous allergic reaction to penicillin had been described. Preclinical serology and laboratory results revealed DNA sequences for cytomegalovirus, a slight increase of the inflammatory marker serum C-reactive protein $(41.6 \mathrm{mg} / \mathrm{l})$ and a normal procalcitonin serum value.
The patient showed rapid deterioration of her condition and was transferred to the intensive care unit. She had a body temperature of $38.6^{\circ}$ Celsius, a heart rate of 140 beats $/ \mathrm{min}$, a blood pressure of $80 / 40 \mathrm{mmHg}$, a respiratory rate of $30 / \mathrm{min}$ and suffered of tarnished consciousness. The electrocardiogram revealed sinus tachycardia and nonspecific ST-T changes. Chest radiography showed prominent pulmonary edema and bilateral pleural effusion (Fig. 1a). Transthoracic echocardiography (TTE) showed highly impaired left ventricular (LV) ejection fraction of $<30 \%$, slight pericardial effusion and no intraventricular thrombus. Laboratory results revealed increased markers of cardiac injury and congestion (high-sensitive Troponin I $3323 \mathrm{ng} / \mathrm{l}$, N-terminal pro brain natriuretic peptide $21053 \mathrm{ng} / \mathrm{l}$ ) and inflammatory response (C-reactive protein $229 \mathrm{mg} / \mathrm{l}$, white blood cell count of $29.3 / \mathrm{nl}$ with $82 \%$ neutrophils), impaired renal function (blood urea nitrogen $56 \mathrm{mg} / \mathrm{dl}$ and creatinine $1.2 \mathrm{mg} / \mathrm{dl}$ ), mild elevation of transaminases (aspartate aminotransferase $289 \mathrm{U} / \mathrm{l}$ and alanine aminotransferase $71 \mathrm{U} / \mathrm{l})$. Empirical broad-spectrum antibiotics and specific antiviral therapy with meropenem, clarithromycin, gentamicin and valganciclovir was established. Chest computed tomography (CT)-scan confirmed prominent pulmonary edema, accumulation of pleural effusion and infiltrates indicating possible pneumonia. There was no evidence of any other infectious focus in the abdominal CT-scan, neurological exanimation including lumbar puncture and gynecological examination. Follow-up TTE showed further decline of left ventricular ejection fraction, combined with rising vasopressor demand, rapidly increasing laboratory signs of cardial decompensation (maximal $\mathrm{N}$-terminal pro brain natriuretic peptide $>70,000 \mathrm{ng} / \mathrm{l}$, lactate dehydrogenase 13,000 U/l) and positive evidence for disseminated intravascular coagulation (thrombocytopenia of $95 / \mathrm{nl}$, prolongation of partial

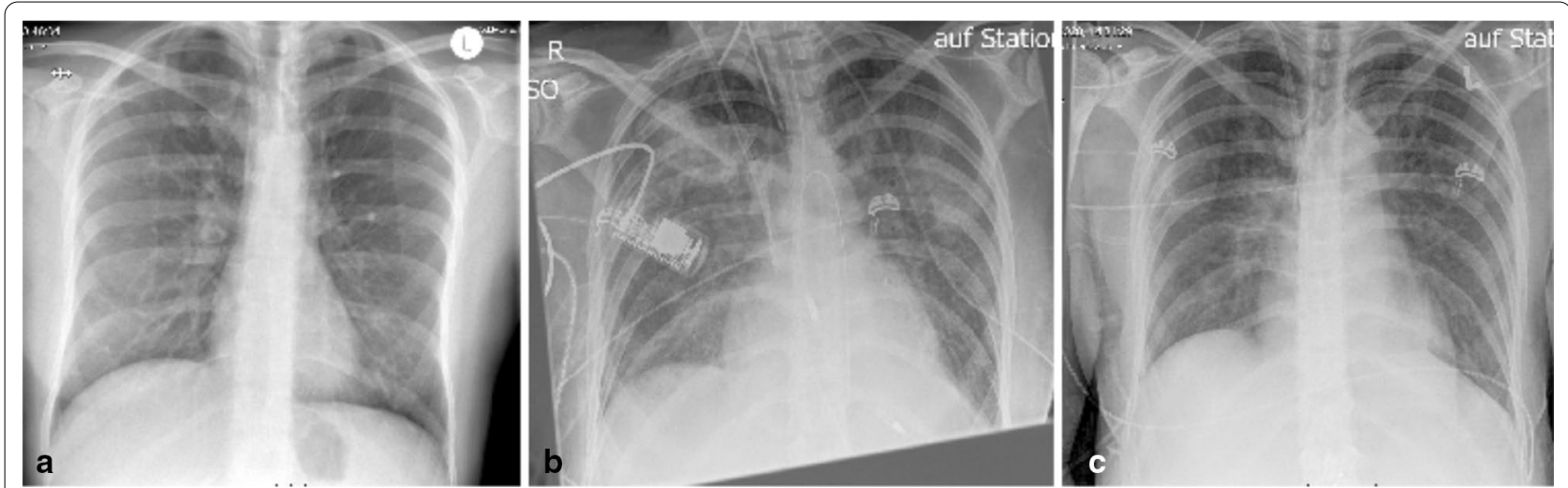

Fig. 1 Chest radiography in supine position and anterior-posterior projection at admission (a), after Impella ${ }^{\circledR}$ placement (b) and at discharge (c). a Marked pulmonary congestion and mild bilateral pleural effusion. b Prominent bilateral pulmonary edema. c Residual pulmonary congestion 
thromboplastin time of $56 \mathrm{~s}$, decreased antithrombin III). An Impella $\mathrm{CP}^{\circledR}$ device was inserted on day 1 shortly after her initial presentation (Fig. 1b), followed by a LV endomyocardial biopsy. Urgent coronary angiography in a patient with cardiogenic shock showed no underlying coronary heart disease (Fig. 2). After initiation of the Impella $\mathrm{CP}^{\circledR}$, the patient displayed further respiratory decline, requiring mechanical ventilation. In light of rising serum lactate levels (maximum $16.0 \mathrm{mmol} / \mathrm{l}$ ), rapidly increasing catecholamine demand and additional imposing right ventricular failure, MCS was escalated via VA-ECMO at the same day. Additionally, the patient was started on inodilatative therapy with levosimendan. Anuria and acute renal failure required renal replacement therapy. Extracorporeal cytokine hemoadsorption via CytoSorb ${ }^{\circledR}$ was installed for $48 \mathrm{~h}$ [17]. Histology of the LV endomyocardial biopsies revealed severe acute EM showing myocardial infiltration with eosinophilic granulocytes, macrophages and CD3 + T cells (Fig. 3). Further laboratory work up revealed no peripheral eosinophilia and increased levels of cytomegalovirus-DNA (437 IE/ $\mathrm{ml})$. Perinuclear anti-neutrophil cytoplasmic antibodies
(p-ANCA) and cytoplasmic anti-neutrophil cytoplasmic antibodies (c-ANCA) were negative. Immunosuppressive therapy with prednisolone was initiated on day $7(1 \mathrm{mg} /$ $\mathrm{kg} /$ day) and continued for 14 days, followed by a dose tapering regimen of $10 \mathrm{mg}$ every 4 weeks. On day 5 both feet showed signs of acute gangrenous necrosis from the tips of all toes to the metatarsales (Fig. 4). Duplex sonography revealed normal flow patterns in all lower extremity arteries and ruled out arterial flow obstruction by femoral ECMO cannulas and Impella ${ }^{\circledR}$ introducer sheath. The level of inotropic support required to maintain stable hemodynamics during "ECMELLA" use constantly decreased. VA-ECMO could be removed after 4 days. LV function recovered quickly to an ejection fraction of $55 \%$ by day 6 , while the patient was still on mechanical circulation Impella ${ }^{\circledR}$ device support and without inotropes. The Impella ${ }^{\circledR}$ device was gradually weaned and could be removed after 9 days. The patient was extubated on day 13, had to be re-intubated due to palate bleeding the same day and could be successfully extubated the following day. Oral heart failure medication (e.g. angiotensin-converting-enzyme inhibitor and $\beta$-blocking agent)

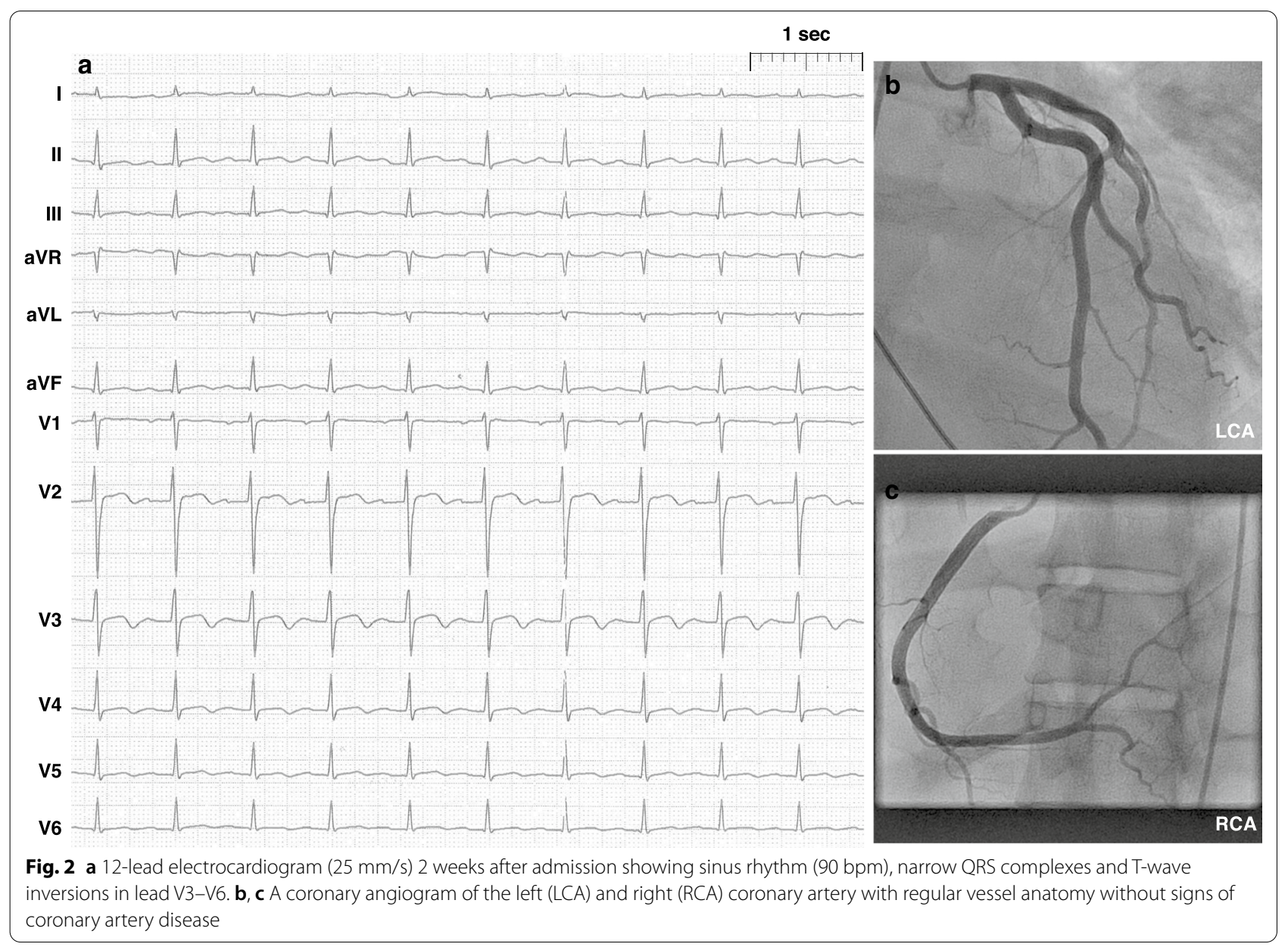




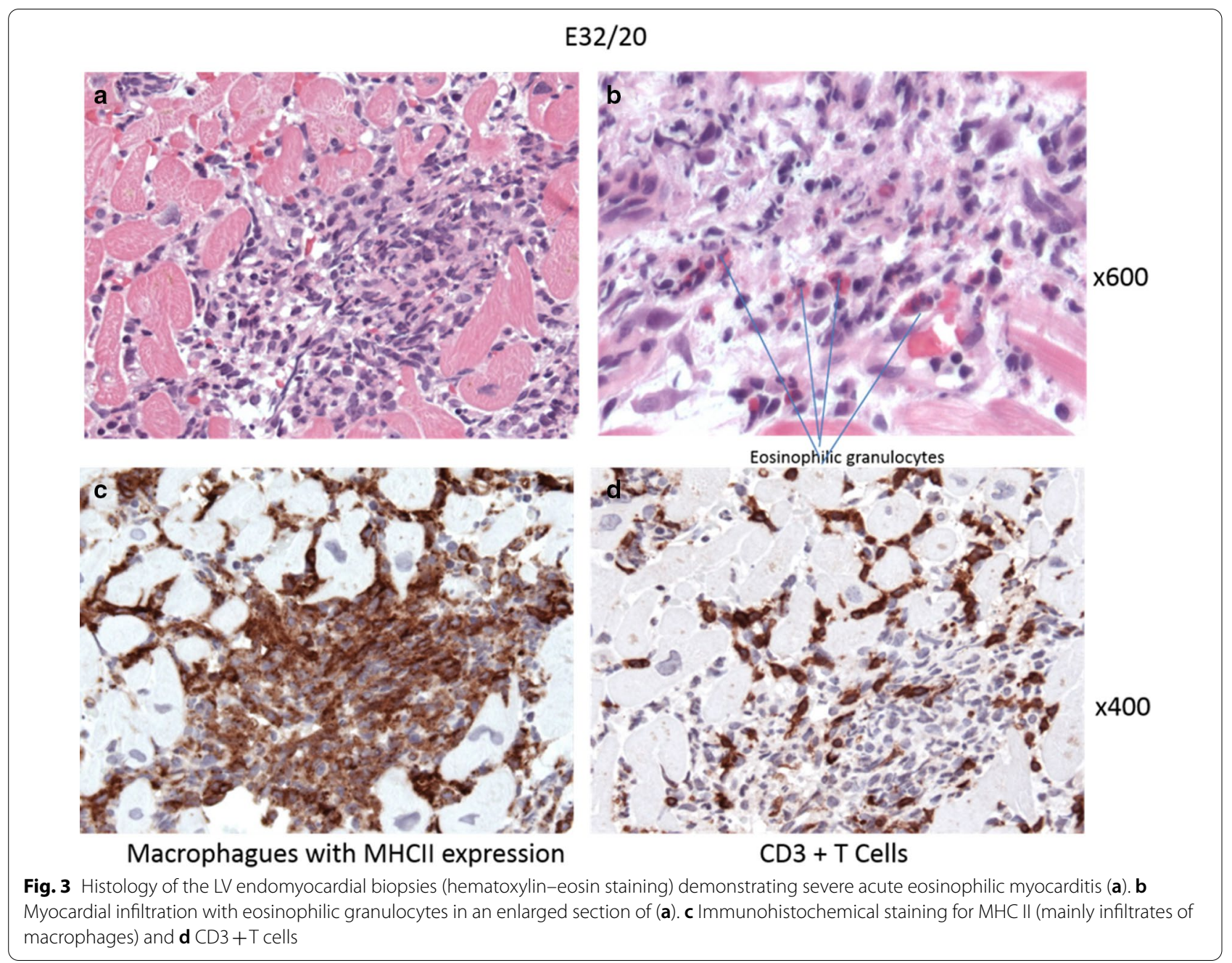

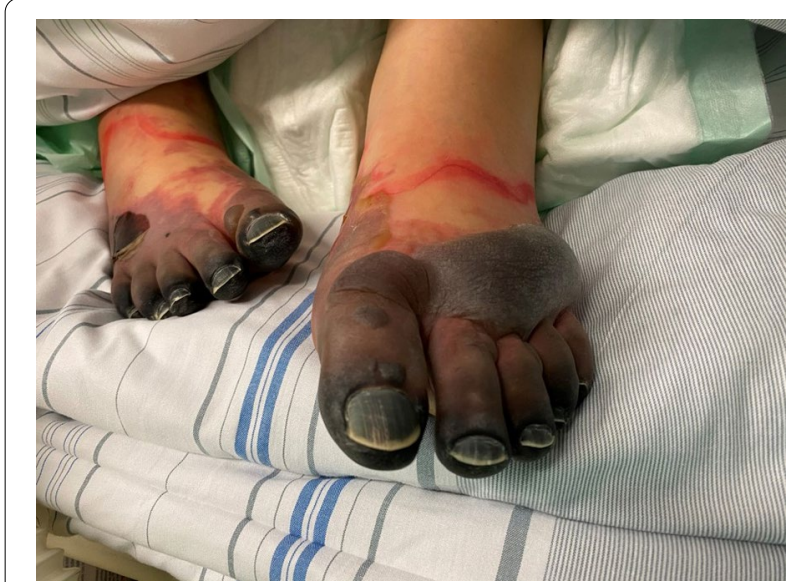

Fig. 4 Photograph of bilateral pedal necrosis from the tips of all toes to the distal metatarsal section was established after ongoing hemodynamic stability. Follow-up chest radiography showed a normalized cardiac silhouette and only residual mild pulmonary edema (Fig. 1c). Cardiac magnetic resonance imaging (MRI) after 28 days demonstrated a borderline reduced systolic $\mathrm{LV}$ - and intact right ventricular function without signs of inflammatory myocardial changes or endomyocardial fibrosis (Fig. 5). During the whole course of hospitalization our patient was in sinus rhythm and did not present any arrhythmic events. The patient was discharged from intensive care unit after 6 weeks in good clinical condition without neurological deficit and renal recovery and was transferred to a rehabilitation center thereafter. In consequent ambulatory follow-up visits, normal parameters were obtained for cardiac function. Six month later, transmetatarsale amputation of the right digiti III-V and resection of the distal phalanxes of the right digitus II and left digiti III-V became necessary. 


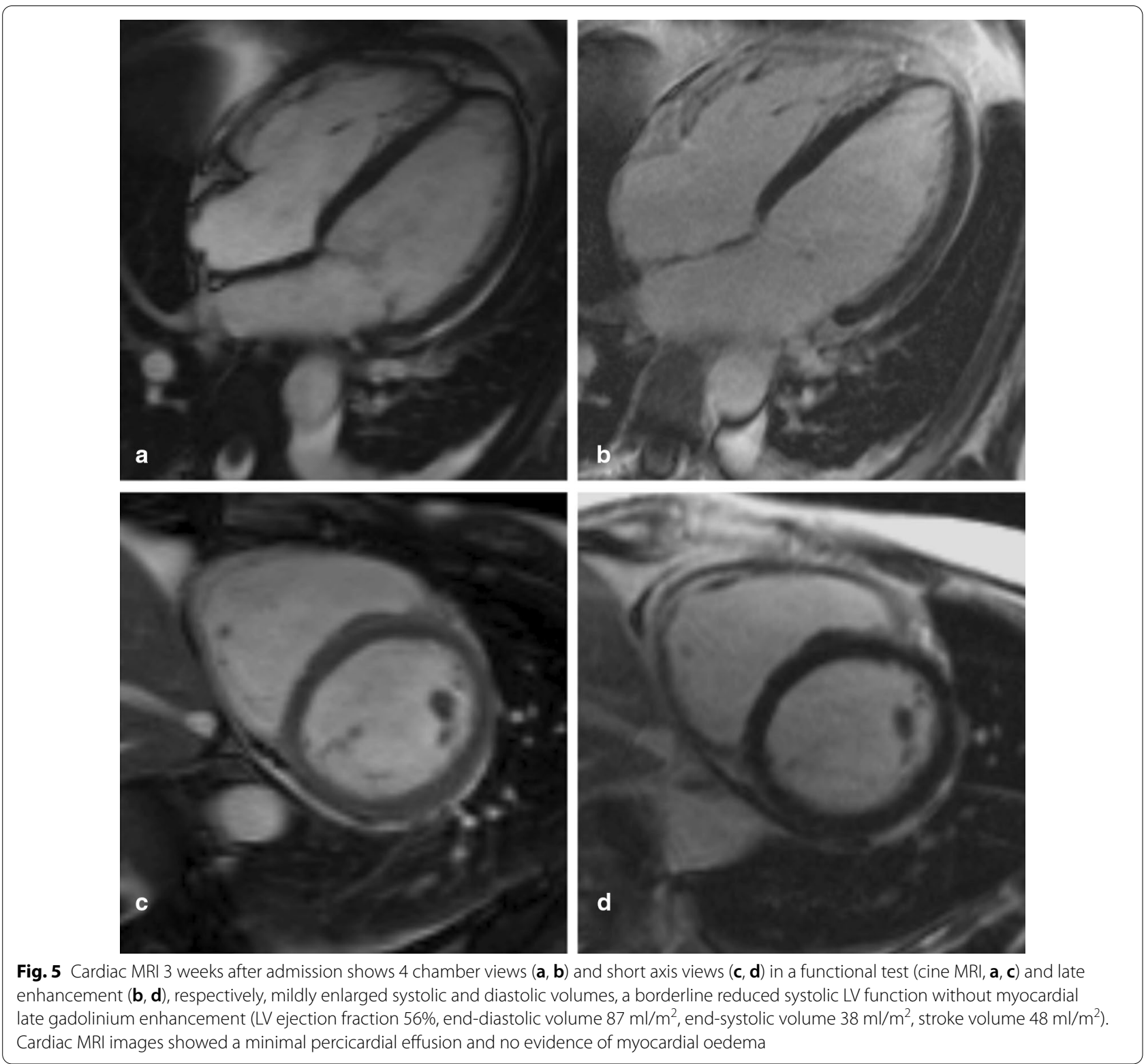

\section{Discussion and conclusions}

Due to the severity of symptoms and extend of endorgan damage seen in this patient, we considered this a case of fulminant myocarditis (FM), characterized by an acute myocardial inflammation leading to cardiogenic shock $[10,11,18]$. As shown in a large registry of 220 patients with histologically proven acute myocarditis, patients with FM have higher rates of cardiac death and heart transplantation compared to non-fulminant myocarditis with $28 \%$ vs. $1.8 \%$ [18]. Stages in EM include myocardial infiltration of eosinophils causing acute necrosis, followed by hypercoagulation, potentially leading to thrombosis, either within the coronary vasculature or the ventricles in up to $13.7 \%$ [1], which can ultimately result in permanent cardiac dysfunction due to myocardial scar formation [18]. Clinical presentation in the often young patients [1] can vary, including embolic cerebral infarctions [19]. After excluding potential embolic sources, vasoconstrictive hypoxia due to high catecholamine demand and disseminated intravascular coagulation was assumed as the most likely cause for the pedal necrosis due to end-organ hypoperfusion in our patient [20]. Moreover, thrombosis is known to complicate MCS [21]. The underlying cause of EM in our patient remained uncertain. Preexisting diseases in the patient's history as Hodgkin's 
disease and ulcerative colitis and the recent pregnancy, however are described as possible associated conditions [1]. Prior to the histological proof of EM, a systemic cytomegalovirus reactivation was also considered as the underlying cause [22]. An important differential diagnosis includes drug reaction (even in absence of detectable peripheral eosinophilia) [23, 24]. In our case, specific information on the timings of any medication use prior to hospitalisation was positive for mesalazine only. Features that point against eosinophilic granulomatosis with polyangiitis as the diagnosis were missing specifities as asthma and blood eosinophilia and ear, nose and throat involvement, although it is known that ANCA is only positive in a proportion of eosinophilic granulomatosis patients [25]. Cardiac MRI showing no significant fibrosis suggests an acute aetiology. Peripheral eosinophilia, as in our case, is absent in up to $25 \%$ of patients with EM [1] and underscores the importance of endomyocardial biopsy in cases of unexplained abrupt LV impairment [26, 27]. Immunosuppression is the most common treatment modality for EM [1], although no clinical trial has tested its efficacy. Remarkable is the observation that the patient started to improve prior to initiation of immunosuppression with a rapid restitution of the biventricular function. Thus, considering also the positivity for cytomegalovirus, the initiated steroid therapy was probably not necessary in our case. The extent of profound cardiac- and multiorgan dysfunction in our patient required immediate MCS allowing time to initiate positive inotropic pharmacotherapy, recommended for the management of patients with acute heart failure to help myocardial recovery and for making the proper diagnosis $[12,13]$. For patients in FM, ECLS via VA-ECMO is the most commonly described MCS [9, 11, 15]. However, it should be taken into account that VA-ECMO increases LV afterload severely, resulting in LV distention and pulmonary edema. The Impella ${ }^{\circledR}$ device provides circulatory support with LV-venting, reduces LV-afterload [10] and has been described as sole therapy in rare cases of acute FM [28, 29]. However, in patients with concomitant right ventricular dysfunction, the Impella is ineffective and can be even counterproductive by exposing the patient to the adverse effects of such support (anemia, complications related to vascular access, distal limb ischemia, infections) [21]. In this specific clinical context, VA-ECMO may be considered as first MCS alternative and, eventually, Impella as LV venting device. In our patient, due to the rapidly developing also right ventricular dysfunction, the Impella ${ }^{\circledR}$ device could not provide adequate hemodynamic support. The MCS strategy was therefore escalated to the ECMELLA concept as the next reasonable step. After additional implantation of a VA-ECMO, the hemodynamic situation gradually stabilized. Continued circulatory support with LV-venting and inodilatative therapy allowed quick recovery of LV function.

Even in fulminant cardiogenic shock due to EM and consecutive biventricular heart failure with multi-organ dysfunction, the ECMELLA concept can be an effective way of MCS therapy providing the time frame for decision making processes, initiation of specific therapy in terms of inotropic and immunosuppression support and to allow cardiac reconstitution. This adds to current evidence, however further research is needed to verify the ECMELLA concept in a wider clinical use.

\section{Abbreviations \\ CT: Computed tomography; ECLS: Extracorporeal life support; EM: Eosinophilic myocarditis; FM: Fulminant myocarditis; LV: Left ventricle; MCS: Mechanical circulatory support; MRI: Cardiac magnetic resonance imaging; TTE: Transtho- racic echocardiography; VA-ECMO: Veno-arterial membrane oxygenation.}

\section{Acknowledgements}

Not applicable.

\section{Authors' contributions}

MB coordinated the study, MB, DUC, ET, HS, DW, NS, SW, EB authors were responsible for the patient care and data collection. DK analyzed the data from cardiac MRI and KK was responsible for the interpretation of the histopatholgy from endomyocardial biopsy. All authors provided comments on the report at various stages of development. All authors read and approved the final manuscript.

\section{Funding}

None.

Availability of data and materials

Please contact author for data requests.

Ethics approval and consent to participate Not applicable.

\section{Consent for publication}

Written consent was obtained from the patient for publication of this case report. I confirm that a copy of the consent form is available for review by the Editor upon request.

\section{Competing interests}

The authors declare that they have no conflicts of interest.

\section{Author details}

${ }_{1}^{1}$ Department of Cardiology, Asklepios Clinic St. Georg, Lohmühlenstraße 5, 20099 Hamburg, Germany. ${ }^{2}$ Department of Cardiopathology, Institute for Pathology, University Hospital Tübingen, Tübingen, Germany. ${ }^{3}$ Department of Radiology, Asklepios Clinic St. Georg, Hamburg, Germany.

Received: 21 September 2020 Accepted: 2 December 2020 Published online: 10 December 2020

\section{References}

1. Brambatti M, Matassini MV, Adler ED, Klingel K, Camici PG, Ammirati E. Eosinophilic myocarditis: characteristics, treatment, and outcomes. J Am Coll Cardiol. 2019;70:2363-75.

2. Pieroni M, Cavallaro R, Chimenti C, Smeraldi E, Frustaci A. Clozapineinduced hypersensitivity myocarditis. Chest. 2004;126:1703-5. 
3. Masi AT, Hunder GG, Lie JT, Michel BA, Bloch DA, Arend WP, Calabrese LH, Edworthy SM, Fauci AS, Leavitt RY, Lightfoot RW, McShane DJ, Mills JA, Stevens MB, Wallace SL, Zvaifler NJ. The American College of Rheumatology 1990 criteria for the classification of churg-strauss syndrome (allergic granulomatosis and angiitis). Arthritis Rheum. 1990;33:1094-100.

4. Enko K, Tada T, Ohgo KO, Nagase S, Nakamura K, Ohta K, Ichiba S, Ujike Y, Nawa Y, Maruyama H, Ohe T, Kusano KF. Fulminant eosinophilic myocarditis associated with visceral larva migrans caused by toxocara canis infection. Circ J. 2009:73:1344-8.

5. Ammirati E, Stucchi M, Brambatti M, Spanò F, Bonacina E, Recalcati F, Cerea G, Vanzulli A, Frigerio M. Oliva F Eosinophilic myocarditis: a paraneoplastic event. Lancet. 2015;385:2546.

6. Ginsberg F, Parrillo JE. Eosinophilic myocarditis. Heart Fail Clin. 2005;1:419-29.

7. Al Ali AM, Straatman LP, Allard MF, Ignaszewski AP. Eosinophilic myocarditis: case series and review of literature. Can J Cardiol. 2006;22:1233-7.

8. Ammirati E, Cipriani M, Lilliu M, Sormani P, Varrenti M, Raineri C, Petrella D, Garascia A, Pedrotti P, Roghi A, Bonacina E, Moreo A, Bottiroli M, Gagliardone MP, Mondino M, Ghio S, Totaro R, Turazza FM, Russo CF, Oliva F, Camici PG, Frigerio M. Survival and left ventricular function changes in fulminant versus nonfulminant acute myocarditis. Circulation. 2017;136:529-45.

9. Tandan S, Meltzer SN, Davila CD, Konstam MA, LeWinter MM. Eosinophilic myocarditis with rapid progression to cardiogenic shock, managed with mechanical support and high-dose corticosteroids. Circ Heart Fail. 2018;11:e004910.

10. Tschöpe C, van Linthout S, Klein O, Mairinger T, Krackhardt F, Potapov EV, Schmidt G, Burkhoff D, Pieske B, Spillmann F. Mechanical unloading by fulminant myocarditis: LV-IMPELLA, ECMELLA, BI-PELLA, and PROPELLA Concepts. J Cardiovasc Transl Res. 2018;12:116-23.

11. Hasegawa-Tamba S, Sugi K, Gatate Y, Sugiyama K, Muramatsu T, Nishimura S, Yasuda M, Fukushima K, Nakano S. Successful bridge-torecovery treatment in a young patient with fulminant eosinophilic myocarditis: roles of a percutaneous ventricular assist device and endomyocardial biopsy. Case Rep Emerg Med. 2019;2019:8236735.

12. Rihal CS, Naidu SS, Givertz MM, Szeto WY, Burke JA, Kapur NK, Kern M, Garratt KN, Goldstein JA, Dimas V, Tu T, Society for Cardiovascular Angiography and Interventions (SCAl); Heart Failure Society of America (HFSA); Society for Thoracic Surgeons (STS); American Heart Association (AHA); American College of Cardiology (ACC). 2015 SCAI/ACC/HFSA/STS clinical expert consensus statement on the use of percutaneous mechanical circulatory support devices in cardiovascular care: endorsed by the American Heart Assocation, the Cardiological Society of India, and Sociedad Latino Americana de Cardiologia Intervencion; Affirmation of Value by the Canadian Association of Interventional Cardiology-Association Canadienne de Cardiologie d'intervention. J Am Coll Cardiol. 2015:65:e7-26.

13. Ponikowski P, Voors AA, Anker SD, Bueno H, Cleland JGF, Coats AJS, Falk V, González-Juanatey JR, Harjola V-P, Jankowska EA, Jessup M, Linde C, Nihoyannopoulos P, Parissis JT, Pieske B, Riley JP, Rosano GMC, Ruilope LM, Ruschitzka F, Rutten FH, van der Meer P, ESC Scientific Document Group. 2016 ESC Guidelines for the diagnosis and treatment of acute and chronic heart failure: The Task Force for the diagnosis and treatment of acute and chronic heart failure of the European Society of Cardiology (ESC)Developed with the special contribution of the Heart Failure Association (HFA) of the ESC. Eur Heart J. 2016;37:2129-200.

14. Werdan K, Gielen S, Ebelt H, Hochman JS. Mechanical circulatory support in cardiogenic shock. Eur Heart J. 2014;35:156-67.

15. Howell E, Paivanas N, Stern J, Vidula H. Treatment of acute necrotizing eosinophilic myocarditis with immunosuppression and mechanical circulatory support. Circ Heart Fail. 2016;9:e003665.

16. Pappalardo F, Schulte C, Pieri M, Schrage B, Contri R, Soeffker G, Greco T, Lembo R, Müllerleile K, Colombo A, Sydow K, De Bonis M, Wagner F,
Reichenspurner H, Blankenberg S, Zangrillo A, Westermann D. Concomitant implantation of Impella ${ }^{\circledR}$ on top of veno-arterial extracorporeal membrane oxygenation may improve survival of patients with cardiogenic shock. Eur J Heart Fail. 2017;19:404-12.

17. Brouwer WP, Duran S, Kuijper M, Ince C. Hemoadsorption with CytoSorb shows a decreased observed versus expected 28-day all-cause mortality in ICU patients with septic shock: a propensity-score-weighted retrospective study. Crit Care. 2019;23:317.

18. Kuchynka P, PalecekT, Masek M, Cerny V, Lambert L, Vitkova I, Linhart A. Current diagnostic and therapeutic aspects of eosinophilic myocarditis. BioMed Res Int. 2016; Article ID 2829583:1-6.

19. Bahlmann E, van der Schalk H, Ghanem A, Kuck KH, Kivelitz D, Laßner D, Terborg C. Brain infarction as initial manifestation of eosinophilic myocarditis. Nervenarzt. 2018;89:200-3.

20. Reyes AJ, Ramcharan K, Harnarayan P, Mooteeram J. Symmetrical digital gangrene after a high dose intravenous infusion of epinephrine and dopamine following resuscitation from cardiac arrest. BMJ Case Rep. 2016. https://doi.org/10.1136/bcr-2016-217977.

21. Subramaniam AV, Barsness GW, Vallabhajosyula S, Vallabhajosyula S. Complications of temporary percutaneous mechanical circulatory support for cardiogenic shock: an appraisal of contemporary literature. Cardiol Ther. 2019;8:211-28.

22. Roubille C, Brunel AS, Gahide G, Kovacsik HV. Quellec A Cytomegalovirus (CMV) and acute myocarditis in an immunocompetent patient. Intern Med. 2010;49:131-3.

23. Thongsri T, Chularojanamontri L. Pichler WJ Cardiac involvement in DRESS syndrome. Asian Pac J Allergy Immunol. 2017;35:3-10.

24. Cho YT, Yang CW, Chu CY. Drug reaction with eosinophilia and systemic symptoms (DRESS): an interplay among drugs, viruses, and immune system. Int J Mol Sci. 2017;18:1243.

25. Groh M, Pagnoux C, Guillevin L. Eosinophilic granulomatosis with polyangiitis (formerly Churg-Strauss syndrome): where are we now? Eur Respir J. 2015;46:1255-8.

26. Ammirati E, Veronese G, Brambatti M, Merlo M, Cipriani M, Potena L, Sormani P, Aoki T, Sugimura K, Sawamura A, Okumura T, Pinney S, Hong K, Shah P, Braun Ö, Van de Heyning CM, Montero S, Petrella D, Huang F, Schmidt M, Raineri C, Lala A, Varrenti M, Foà A, Leone O, Gentile P, Artico J, Agostini V, Patel R, Garascia A, Van Craenenbroeck EM, Hirose K, Isotani A, Murohara T, Arita Y, Sionis A, Fabris E, Hashem S, Garcia-Hernando V, Oliva F, Greenberg B, Shimokawa H, Sinagra G, Adler ED, Frigerio M, Camici PG. Fulminant versus acute nonfulminant myocarditis in patients with left ventricular systolic dysfunction. J Am Coll Cardiol. 2019;74:299-311.

27. Cooper LT, Baughman KL, Feldman AM, Frustaci A, Jessup M, Kuhl U, Levine GN, Narula J, Starling RC, Towbin J, Virmani R. The role of endomyocardial biopsy in the management of cardiovascular disease: a scientific statement from the American Heart Association, the American College of Cardiology, and the European Society of Cardiology. J Am Coll Cardiol. 2007;50:1914-31.

28. Fox H, Farr M, Horstkotte D, Flottmann C. Fulminant myocarditis managed by extracorporeal life support (Impella(R) CP): a rare case. Case Rep Cardiol. 2017. https://doi.org/10.1155/2017/9231959.

29. Suradi H, Breall JA. Successful use of the Impella device in giant cell myocarditis as a bridge to permanent left ventricular mechanical support. Tex Heart Inst J. 2011;38:437-40.

\section{Publisher's Note}

Springer Nature remains neutral with regard to jurisdictional claims in published maps and institutional affiliations. 